\title{
Parametric Study for Adsorption of Sodium Rhodizonate on Chitosan
}

\section{Kanwal Rashid*, Ayesha Saddiqa and Arfa Nawaz}

Department of Chemical Engineering, COMSATS Institute of Information Technology, Defense Road, Off Raiwind Road, Lahore, Pakistan

\begin{abstract}
Sodium Rhodizonate, a derivative of Rhodizonic acid is widely used in industry and also for detection of different metals in waste water. In the present work the ability to remove Sodium Rhodizonate from waste water is studied using Chitosan as an adsorbent material. The studies are approved as a function of adsorbent amount, contact time, $\mathrm{pH}$ and temperature. Acidic $\mathrm{pH}$ (1.5-2), medium temperature (45-55) were found to be favorable for adsorption of Sodium Rhodizonate. Maximum adsorption of chitosan is obtained after 70 minute. Similarly the initial concentration Equilibrium isotherm was measured experimentally at different temperatures. It has been constructally shown that chitosan is a highly promising material for the removal of Sodium Rhodizonate.
\end{abstract}

Keywords: Adsorption; Sodium rhodizonate; Chitosan; Waste water

\section{Introduction}

Water Pollution by dyes and heavy metals is a highly potential hazard to aquatic ecosystem as many of these metals and dyes are highly toxic, even when present in low concentrations. Dyes and heavy metals tend to accumulate in living cells and can cause severe problems to both human health and aquatic life. Most transition metals and some traces of dyes found in the wastewater during dye manufacturing are phenol, aniline, organic acid and benzene and their derivatives [1]. Not only waste of industries polluting the water but some other processes like mining agriculture wastes including cyanide and toxic heavy metals, improper sewerage treatment that is sometimes discharged without treatment into water bodies. Eliminating the concentration of heavy metals and dyes from the aquatic systems is very important so diversified engineered technologies are commonly applied in waste water treatment and refining industry effluents. These methods include filtration, ion exchange resins, Chlorination, Activated charcoal, Sedimentation [2]. Some of the methods are expensive and time consuming. In the current experiment waste water is treated with adsorption method.

Many researchers have mentioned that low cast adsorbent material can also be used for the treatment of waste water like, pine sawdust [3], activated charcoal prepared from Ricinus communis leaves [4] wood apple shell [5], rejected tea [6] and many other adsorbent. It is proved that low cast adsorbent material are very effective for the recycling of waste water especially for the adsorption of heavy metals [7] and dyes and also eco friendly.

In our investigations we used chitosan as a low cost adsorbent material, obtained from Chitin abundantly found natural polymer. Chitosan is de-acetylated form of Chitin which is biopolymer [8] that comes from crustacean shells and has ability to adsorbed a great variety of dyes. The strong affinity of dyes for this is explained by the relatively high proportion of nitrogen sites [9]. A frequent method for the production of chitosan is de-acetylating of chitin [10,11]. This reaction gives $98 \%$ product when allowed to go to completion (complete deacetylating). There are many uses of chitosan. e.g in agriculture can be used for coating of fertilizers, pesticides, insecticides, and herbicides for their restricted release to soil.

In waste water treatment, chitosan is used as flocculating and chelating agents, for the elimination of heavy metals and dyes. The dye under investigation is a derivative of Rhodizonic acid. This dye widely use for the detection of different metal ions like barium, lead, iron, strontium etc. at laboratory scale and gives colored precipitates when added to Strontium and Barium [12]. It is also used as metal titration indicator [12], in chromatography [13] and in forensic applications [14]. The present effort is devoted to its removal from waste water.
Different parameters like temperature, adsorbent dose, $\mathrm{pH}$, adsorbent concentration and shaking time support the experiment.

\section{Materials and Methods}

Sodium Rhodizonate $\left(\mathrm{C}_{6} \mathrm{Na}_{2} \mathrm{O}_{6}\right.$, named as $3,4,5,6-$ tetraoxocyclohexene-1, 2-diol disodium salt) excites in dark brown solid and stable salt. Its molecular weight is 214.04 and melting point $300^{\circ} \mathrm{C}$. The aqueous solution gives orange to yellow color and decomposes in a few days, even in the refrigerator. Chemicals, $\mathrm{NaOH}$, $\mathrm{HCl}$, Liquid ammonia, were of analytical grade and used without further processing. The stock solution of dye is prepared in de-ionized water by dissolving $1 \mathrm{gm}$ of dye in $1000 \mathrm{ml}$ of water. Standard solutions were made from the stock solutions in the concentration range $0.001 \%$ $0.005 \%$.

Adsorption studies were carried out at $25^{\circ} \mathrm{C}$. The $\mathrm{pH}$ of the solutions were adjusted for acidic media with acetic acid and for basic with liquid ammonia. A specific amount of adsorbent (Chitosan) was added to the sample and allowed sufficient time for adsorption equilibrium. Then the solution was filtered with filter paper and dye concentration were determine in the filtrate at $\lambda \max =320 \mathrm{~nm}$. The outcome of various parameters on the adsorption rate were observed by changing contact time ' $\mathrm{t}$ ' (20-90 $\mathrm{min}$ ), Initial concentration of dye $(1 \mathrm{mg} / 100 \mathrm{ml})$, adsorbent amount $(0.05 \mathrm{gm})$, adsorbent size $(0.1 \mathrm{gm}$ $0.6 \mathrm{gm})$, initial $\mathrm{pH}$ of the solution (1-6), and temperature $\left(40-90^{\circ} \mathrm{C}\right)$. The quantity of dye adsorption (Q.D) percentage at any instant of time was calculated by the following equation.

$$
\text { Sodium rodizonate } \%=\frac{C_{i}-C_{a}}{C_{i}} \times 100
$$

Where $\mathrm{C}_{\mathrm{i}}$ is initial concentration and $\mathrm{C}_{\mathrm{a}}$ is absorbed concentration.

\section{Results and Discussion}

The amount of Sodium Rhodizonate adsorbed over Chitosan was

*Corresponding author: Kanwal Rashid, Department of Chemical Engineering, COMSATS Institute of Information Technology, Defense Road, Off Raiwind Road, Lahore, Pakistan,Tel: 111001007, E-mail: krasheed@ciitlahore.edu.pk

Received November 03, 2014; Accepted April 17, 2015; Published April 23, 2015

Citation: Rashid K, Saddiqa A, Nawaz A (2015) Parametric Study for Adsorption of Sodium Rhodizonate on Chitosan. J Environ Anal Chem 2: 136 doi:10.4172/2380-2391.1000136

Copyright: @ 2015 Rashid K, et al. This is an open-access article distributed under the terms of the Creative Commons Attribution License, which permits unrestricted use, distribution, and reproduction in any medium, provided the original author and source are credited. 
studied by varying $\mathrm{pH}$ range 1.5 to 6.5 and adsorption was bring into being to decrease with increasing $\mathrm{pH}$ (Figure 1). Chitosan act as a weak base. At low $\mathrm{pH}$, amino group of Chitosan take the protons available in solution. The profile shows that the higher adsorption value of at acidic $\mathrm{pH} 1.5$, which appears to be as best values of $\mathrm{pH}$ for adsorption. The adsorption was checked at $35^{\circ} \mathrm{C}$.

The Concentration of dye against the adsorbent material (Figure 2) at 35,45 and $55^{\circ} \mathrm{C}$ shows that the uptake of dye increases with the change in quantity of dye at each temperature. Sodium Rhodizonate had taken $\times 10^{-3} \mathrm{M}$ to $\times 10^{-2} \mathrm{M}$ at different temperatures and with different volume at $\mathrm{pH}$ 1.5.The adsorption of the dye is directly proportional to temperature which shows that the reaction probably endothermic.

Linear forms of Langmuir adsorption isotherm were obtained for the different temperatures. For Langmuir adsorption the following equation can be used (Figure 3 ).

$$
1 / \mathrm{qe}=1 / \mathrm{Q}_{\mathrm{O}}+\left(1 / \mathrm{b} \mathrm{Q}_{\mathrm{O}}\right)(1 / \mathrm{Ce})
$$

Where Ce is molar concentration of solution at the time of equilibrium, $\mathrm{Q}_{\mathrm{O}}$ number of moles of solute absorbed, $\mathrm{b}$ is constant.

\section{Kinetic properties}

In kinetic properties there are two factors contact time and amount of adsorbent. Contact time of dye is one of the important factors of kinetic properties to measure adsorption. The percentage of Sodium Rhodizonate adsorption is observed as a function of contact time in the range of 20-90 minutes. The results are shown in Figure 4.

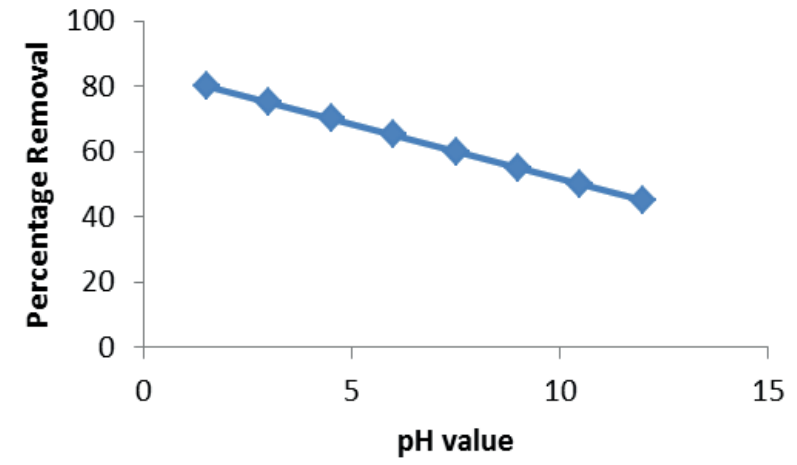

Figure 1: Effect of $\mathrm{pH}$ on Sodium Rhodizonate $\left(1 \times 10^{-3} \mathrm{M}\right)$ by Chitosin $(0.1 \mathrm{gm})$ at $35^{\circ} \mathrm{C}$.

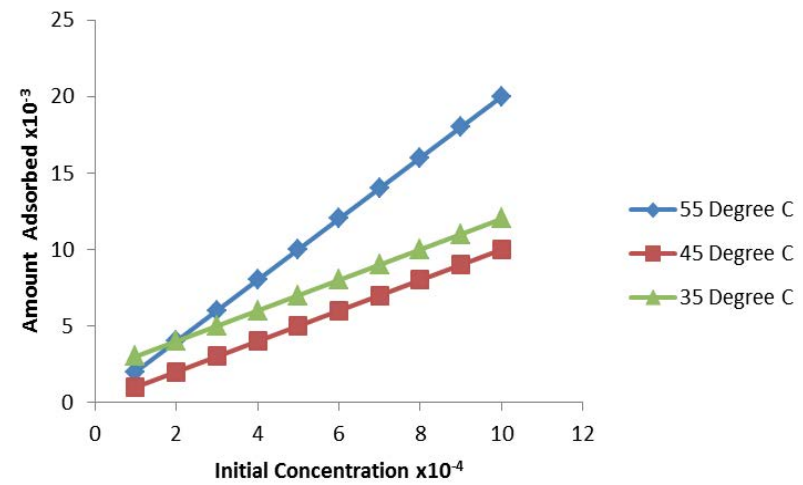

Figure 2: Effect of concentration for the removal of Sod. Rhodizonate by Chitosan $(0.1 \mathrm{~g})$ at $1.5 \mathrm{pH}$

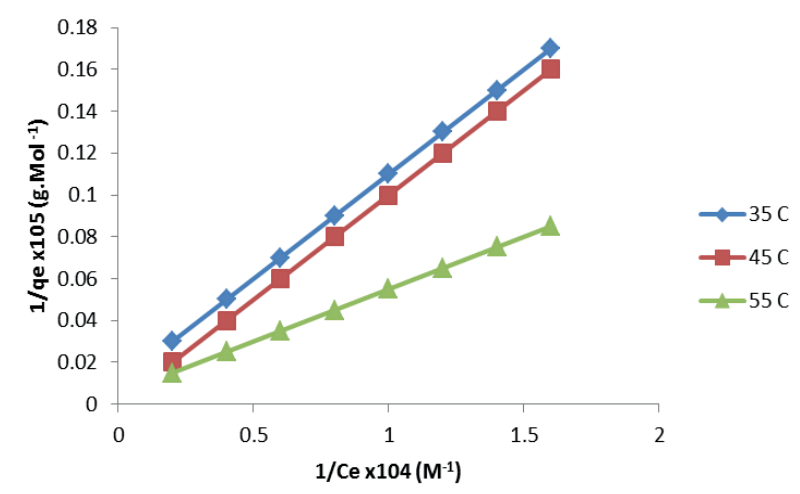

Figure 3: Langmuir isotherms for adsorption of .Rhodizonate by Chitosan $(0.1 \mathrm{~g})$ at $1.5 \mathrm{pH}$

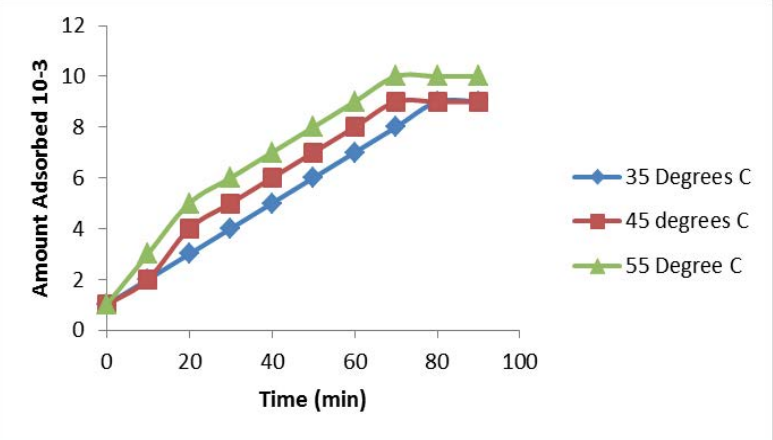

Figure 4: The effect of contact time for adsorption of .Rhodizonate by Chitosan $(0.1 \mathrm{~g})$ at $1.5 \mathrm{pH}$.

The adsorption characteristics indicated a rapid uptake of the adsorbent within the time range of 20-90 minutes. A steady raise was observed. The maximum adsorption was at $70 \mathrm{~min}$. The adsorbent rate however becomes constant after 70 minutes.

\section{Amount of adsorbent}

The amount of adsorbent also an important feature (Figure 5) and it was found that the adsorption of the dye is directly proportional to amount of dye from 0.01 to $0.1 \mathrm{~g}$. The further increase in the amount did not affect the adsorption and it remains constant.

\section{Conclusion}

The results of our investigation are technically very promising and economically feasible and efficiently used for the taking away of Sodium Rhodizonate from the waste water. Different parameters observed during the process of investigations revealed that the temperature, volume of the dye, $\mathrm{pH}$, contact time and adsorbent dose all were important factors to controlling adsorption at different temperatures. According to results adsorption is maximum at $1.5 \mathrm{pH}$ of $1 \times 10^{-3} \mathrm{M}$ solution. For Initial concentration of dye Sodium Rhodizonate had taken $\times 10^{-3} \mathrm{M}$ to $\times 10^{-2} \mathrm{M}$ at different temperatures and with different volume at $\mathrm{pH}$ 1.5.The adsorption of the dye also increases with increase in temperature. The effect of contact time for adsorption was measured for Sod. Rhodizonate by Chitosan which is maximum at 70 minutes. A linear plot of Langmuir isotherm confirms the applicability of adsorption ability of Chitosan. Langmuir isotherms showed that the reaction is favorable at $\mathrm{pH} 1.5$, temperature $55^{\circ} \mathrm{C}$. For adsorption of 


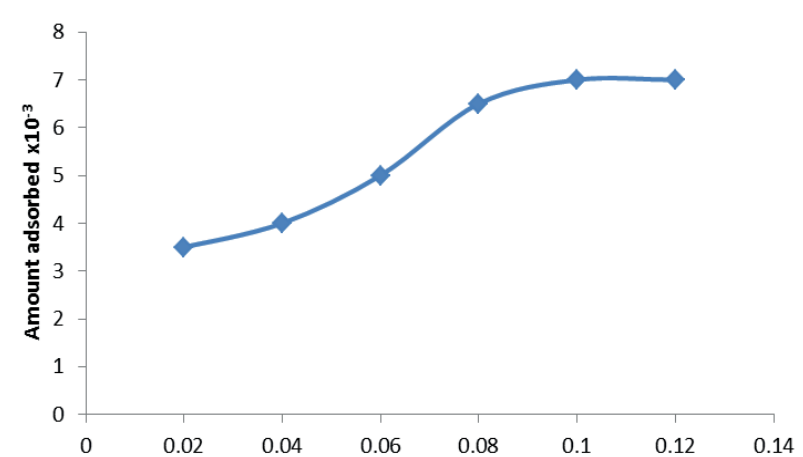

Figure 5: The effect of amount of adsorbent for adsorption of Sod Rhodizonate by Chitosan $(0.01$ to $0.1 \mathrm{~g})$ at $1.5 \mathrm{pH}$.

Sodium Rhodizonate. The amount of adsorbent is also important and it was observed that the increase in amount shows the adsorption capability of the dye. Maximum ability to absorb the dye of Chitosan is at $0.1 \mathrm{~g}$.

\section{Acknowledgements}

The author thanks to the Govt. College University, Lahore, Pakistan for the Lab facilities.

\section{References}

1. Nigam P, Armour G, Banat IM, Singh D, Marchant R (2000) Physical removal of textile dyes from effluents and solid-state fermentation of dye-adsorbed agricultural residues. Bioresource Technology 72: 219-226.

2. George Z. Kyzas, Saeid Azizian, Margaritis Kostoglou (2014) Nove Approaches in Designing Natural/Synthetic Materials for Environmental Applications. Advances in Materials Science and Engineering 2015: 1
3. Ntengwe $F$ (2005) An overview of industrial wastewater treatment and analysis as means of preventing pollution of surface and underground water bodies - the case of Nkana Mine in Zambia. Physics and Chemistry of the Earth 30: 726-734

4. Makeswari M, Santhi T (2014) Adsorption of $\mathrm{Cr}(\mathrm{VI})$ from aqueous solutions by using activated carbons prepared from $<\mathrm{i}>$ Ricinus communis $<\mathrm{i}>$ leaves: Binary and ternary systems. Arabian Journal of Chemistry.

5. Sharma P, Kaur H, Sharma M, Sahore V (2011) A review on applicability of naturally available adsorbents for the removal of hazardous dyes from aqueous waste. Environmental monitoring and assessment 183: 151-195.

6. Aziz HA, Adlan MN, Ariffin KS (2008) Heavy metals (Cd, Pb, Zn, Ni, Cu and $\mathrm{Cr}(\mathrm{III}))$ removal from water in Malaysia: Post treatment by high quality limestone. Bioresource Technology 99: 1578-1583.

7. Ramakrishna KR, Viraraghavan T (1997) Dye removal using low cost adsorbents. Water Science and Technology 36: 189-196.

8. Muzzarelli RA, Weckx M, Filippini O, Sigon F (1989) Removal of trace metal ions from industrial waters, nuclear effluents and drinking water, with the aid of cross-linked $<\mathrm{i}>\mathrm{N}<\mathrm{i}>$-carboxymethyl chitosan. Carbohydrate polymers 11: 293-306.

9. Phongying S, Aiba SI, Chirachanchai S (2007) Direct chitosan nanoscaffold formation via chitin whiskers. Polymer 48: 393-400.

10. Ravi Kumar MN (2000) A review of chitin and chitosan applications. Reactive and functional polymers $46: 1-27$

11. Pillai C, Paul W, Sharma CP (2009) Chitin and chitosan polymers: Chemistry, solubility and fiber formation. Progress in Polymer Science 34: 641-678.

12. Feigl F, Suter HA (1942) Analytical use of sodium rhodizonate. Industrial \& Engineering Chemistry Analytical Edition 14: 840-842.

13. Burma D (1953) Separation of lithium, sodium and potassium present as sulphates and citrates by means of paper chromatography. Analytica Chimica Acta 9: 513-517

14. Andreola S, Gentile G, Battistini A, Cattaneo C, Zoja R (2011) Forensic applications of sodium rhodizonate and hydrochloric acid: a new histological technique for detection of gunshot residues. Journal of forensic sciences 56 : 771-774. 